\title{
Piso Pegajoso, Teto de Vidro e Abelha Rainha: a tríplice barreira imposta pela conomia sexista
}

\author{
Sticky Floor, Glass Ceiling and Queen Bee: The triple barrier imposed by the sexist economy \\ Piso pegajoso, techo de cristal y abeja reina: la triple barrera impuesta por la economía sexista
}

Recebido: 15/05/2021 | Revisado: 20/05/2021 | Aceito: 20/06/2021 | Publicado: 04/07/2021

Kesia Kiss Nunes

ORCID: https://orcid.org/0000-0001-7988-4790 Universidade Federal de Goiás, Brasil

E-mail: kesiasejudh@gmail.com

Angelita Pereira de Lima

ORCID: https://orcid.org/0000-0002-11752-8162

Universidade Federal de Goiás, Brasil

E-mail: angelita_lima@ufg.br

\begin{abstract}
Resumo
O capitalismo possui suas bases fundadas na economia sexista, na qual a mulher representa meio para aquisição de lucro fácil. Partindo dessa premissa, o presente trabalho visa, por meio de pesquisa bibliográfica, estudar o "piso pegajoso"; o "teto de vidro" e o fenômeno "abelha rainha" como tríplice barreira encontrada pelas mulheres para alcançar cargos de comando, bem como as consequências desse modelo econômico.
\end{abstract}

Palavras-chave: Economia sexista; Piso pegajoso; Teto de vidro; Fenômeno "Abelha Rainha".

\begin{abstract}
Capitalism has its bases founded on the sexist economy, where women represent a means for the acquisition of easy profit. Based on this premise, the present work aims, through bibliographic research, to study the "sticky floor"; the "glass ceiling" and the "queen bee" phenomenon as a triple barrier encountered by women to reach command positions, as well as the consequences of this economic model.

Keywords: Sexist economy; Sticky floor; Ceiling glass; "Queen Bee" phenomenon.

\section{Resumen}

El capitalismo tiene sus bases fundadas en la economía sexista, en la que las mujeres representan un medio para la adquisición de ganancias fáciles. Partiendo de esta premisa, el presente trabajo pretende, a través de la investigación bibliográfica, estudiar el "piso pegajoso"; el fenómeno del "techo de cristal" y la "abeja reina" como una triple barrera que encuentran las mujeres para alcanzar puestos de mando, así como las consecuencias de este modelo económico. Palabras clave: Economía sexista; Piso pegajoso; Vidrio de techo; Fenómeno "Abeja Reina".
\end{abstract}

\section{Introdução}

Durante parte da idade média, operava-se uma organização econômica denominada feudalismo, em que o sistema de feudos cingia-se na posse da terra ou renda repassadas pelos nobres aos servos e, estes por sua vez, dava em troca sua fidelidade e trabalho, isto é servidão. Esse sistema econômico revestia-se de autossuficiência da produção para consumo local e eventuais excedentes das colheitas de gêneros alimentícios destinavam-se às trocas entre os feudos adjacentes. A medida em que os intercâmbios aumentavam, o sistema feudal enfraquecia e o comércio ganhou terreno, desembocando na valorização do dinheiro em detrimento da terra, onde as relações do meio de produção sedimentou-se na mão de obra livre e assalariada dos proletariados, que do seu suor, ofertava lucros exponenciais a recém surgida classe burguesa (Marx; Engels, 2019).

As mulheres desse período se insurgiram contra esse novo sistema econômico e foram severamente oprimidas pelo capitalismo, que contou com a participação da igreja para perseguir e queimar as mulheres detentoras de conhecimento que desafiavam os interesses do capital, sobretudo durante a "peste negra", que dizimou boa parte da população e ameaçou a sobrevivência do capital por ausência de mão de obra, sendo necessário condenar as mulheres que possuíam saberes aptos à evitar a gravidez a serem queimadas na fogueira sob acusação de tratarem-se de bruxas, por atrapalharem os meios de 
produção que viam nos corpos femininos o grande pilar do capital - a fábrica de mão de obra necessária a oxigenação do capitalismo (Federici, 2017)

Desse modo, o capitalismo deita suas raízes sobre a exploração das mulheres, nutrindo-se de uma economia sexista amplamente difundida, em que os corpos femininos representam mão de obra barata e/ou não paga, o que atende os interesses do capital. E para a manutenção desse sistema é fundamental o uso de expedientes que impeçam a mulher de alcançar cargos de poder que são ocupados majoritariamente por homens.

Com efeito, o sistema capitalista é moldado pela histórica opressão e exploração das mulheres. Esse sistema (Aruzza; Bhattacharya; Fraser, 2019) não vive apenas da exploração do trabalho assalariado; ele também vive à custa do trabalho não remunerado que produz os seres humanos e as comunidades, baseado na busca incansável pelo lucro ilimitado, pois sua lógica é direcionada a recrutar o trabalho não remunerado do cuidado desempenhado pelas mulheres.

Embora o capitalismo não tenha inventado a subordinação das mulheres, na perspectiva das autoras,

estabeleceu outros modelos, notadamente "modernos", de sexismo, sustentados pelas novas estruturas institucionais. Seu movimento fundamental foi separar a produção de pessoas da obtenção de lucro, atribuir o primeiro trabalho às mulheres e subordiná-lo ao segundo. Com esse golpe, o capitalismo reinventou a opressão das mulheres e, ao mesmo tempo virou o mundo de cabeça para baixo (...) Longe de ser valorizada por si mesma, a produção de pessoas é tratada como mero meio para gerar lucro. Como o capital evita pagar por esse trabalho, na medida do possível, ao mesmo tempo que trata dinheiro como essência e finalidade supremas, ele relega quem realiza o trabalho de reprodução social a uma posição de subordinação - não apenas para os proprietários do capital, mas também para os trabalhadores e trabalhadoras com maior remuneração, que podem descarregar suas responsabilidades em relação a esse trabalho sobre outras pessoas. Essas "outras pessoas" são, em sua grande medida, do sexo feminino. Pois, na sociedade capitalista, a organização da reprodução social se baseia no gênero: ela depende dos papéis de gênero e entrincheira-se na opressão de gênero. (Aruzza; Bhattacharya; Fraser, 2019, p. 38-40, destaque das autoras)

Nesse passo, o capitalismo encontra sua fonte de sobrevivência estruturada na economia sexista, que executa de maneira eficiente esse projeto, impondo as barreiras do piso pegajoso, teto de vidro e fenômeno abelha com vistas a impedir a presença da mulher em cargos de prestígio a fim de evitar a desnaturalização do capital, que tem seu DNA ${ }^{1}$ no sexismo econômico e desigualdade de classe.

Assim, propomos um estudo teórico bibliográfico, colimando explorar a dimensão da economia sexista enviesada pelas três barreiras projetadas pelo piso pegajoso, teto de vidro e abelha rainha, a fim de saber como esses três fenômenos projetam suas barreiras sobre as mulheres no exercício da profissão e quais os seus efeitos na sociedade.

\section{Metodologia}

Para desenvolver o estudo acerca dos fenômenos do piso pegajoso, teto de vidro e abelha rainha como tripla barreira à ascensão profissional das mulheres no mercado de trabalho a pesquisa teórico-reflexiva, construída com base na teoria social marxista, salário do patriarcado e reprodução social de Silvia Federici. Outrossim, foi utilizada a pesquisa qualitativa, haja vista que ao contrário dos métodos das ciências sociais, a qualitativa abarca como objeto de estudo praticamente todo acontecimento da vida real Yin, R. K. (2016), sendo as mulheres proletariadas uma delas, para tanto buscamos também suporte na revisão bibliográfica partindo do conceito de economistas feministas acerca do piso pegajoso, teto de vidro e abelha rainha, perpassando pelo princípio da dignidade da pessoa humana.

Finalmente, o presente artigo foi sedimentado na abordagem histórica, haja vista que os estudos de natureza sócio histórica, nos permite compreender os diferentes grupos humanos e bibliográfica colimando possibilita embasamento teórico.

\footnotetext{
${ }^{1}$ Ácido desoxirribonucleico, composto por, segundo Paulino, de bases nitrogenadas denominadas citosina, guanina, adenina e timina, com duplo filamento de nucleotídeos, cuja principal característica é sua capacidade de autoduplicação (ou reduplicação), de forma a originar cópias exatas de si mesmo.
} 


\section{Piso Pegajoso (Sticky Floor) e Teto de Vidro (Glass Ceiling)}

Segundo a Organização das Nações Unidas (ONU), em estudo realizado pelo Programa das Nações Unidas para o Desenvolvimento (PNUD), 90\% da população mundial tem algum tipo de preconceito contra as mulheres. Isso reflete no mercado de trabalho, onde os homens são vistos como detentores natos de competência, racionalidade e habilidade para o assumirem cargos de direção, ao passo que as mulheres são retratadas como emotivas, sem habilidades e até incompetentes para o desempenho de cargos de poder (Folha Dirigida, 2020, online). Disso decorre a primeira barreira encontrada pelas mulheres na trajetória profissional, o piso pegajoso (Sticky Floor).

Criado por economistas feministas, o piso pegajoso (Sticky Floor) traduz-se em uma segregação das mulheres no plano horizontal do mercado de trabalho, onde são confinadas às funções que remetem às atividades domésticas ou “economia do cuidado", conforme magistério da economista Brena Paula Magno Fernandez:

A metáfora do "piso pegajoso" refere justamente à dificuldade que as mulheres concentradas nestes setores e empregos menos valorizados economicamente encontram para alterar a sua situação. Já os homens concentram-se preferencialmente nos setores primário e secundário, onde além de receberem salários que em média são mais elevados, também desfrutam de melhores condições de trabalho, no sentido de seguridade social (Fernandez, 2019, p. 88-89).

De acordo com a autora, o piso pegajoso é uma metáfora adequada para demonstrar a naturalização da vinculação das mulheres em determinados postos de trabalhos que são desqualificados e mal remunerados, sobretudo os postos do setor terciário, mas que têm reflexos nas demais atuações profissionais das mulheres. Observa-se que, o piso pegajoso como primeira barreira criada pela economia sexista, aleita vigorosamente o capital, uma vez que esse preconceito de gênero desencadeia disparidades salariais gritantes entre homens e mulheres, haja vista que as funções enviesadas pelos afazeres domésticos são desvalorizadas, conforme preconiza a filósofa Angela Davis “como as tarefas domésticas não geram lucro, o trabalho doméstico foi naturalmente definido como uma forma inferior de trabalho, em comparação com a atividade assalariada capitalista" (Davis, 2016, p. 230).

Com isso, a economia sexista coloca nos ombros das mulheres as atividades não remuneradas, como por exemplo, os cuidados com as crianças e limpeza do lar, o que acarreta exaustão nessas mulheres que são submetidas à jornada dupla e até tripla de trabalho. De acordo com o Instituto Brasileiro de Geografia e Estatística (IBGE), em 2018, (Folha Dirigida, 2020, online) as mulheres trabalham, em média, três horas por semana a mais que os homens, combinando trabalhos remunerados, afazeres domésticos e cuidados de pessoas. Para a filósofa Angela Davis

Os incontáveis afazeres que, juntos, são conhecidos como "tarefa domésticas" - cozinhar, lavar a louça, lavar a roupa, arrumar a cama, varrer o chão, ir às compras etc. -, ao que tudo indica, consomem, em média, de 3 mil a 4 mil horas do ano de uma dona de casa. Por mais impressionante que essa estatística seja, ela não é sequer uma estimativa da atenção constante e impossível de ser quantificada que as mães precisam dar às suas crianças (Davis, 2016, p. 225).

Em decorrência do piso pegajoso, as mulheres comumente estarão "grudadas" em profissões remetem às domésticas e dever de cuidado como garçonete, enfermeira, pedagoga. No que se refere à esta última, na educação infantil encontramos majoritariamente mulheres assumindo esta "missão", uma vez que nas palavras da pesquisadora Guacira Lopes Louro

De um modo talvez um tanto esquemático, se poderia dizer que a representação dominante do professor homem foi e provavelmente ainda seja - mais ligada à autoridade e ao conhecimento, enquanto que a da professora mulher se vinculava mais ao cuidado e ao apoio "maternal" à aprendizagem dos/das alunos/as (Louro, 1997, p. 111).

Além do piso pegajoso, outra barreira é colocada no caminho das mulheres - o teto de vidro (glass ceiling) - que se encontra no plano vertical, segregando-as no porão da pirâmide social do trabalho, representando uma barreira invisível (transparente), mas firme o suficiente para impedir que as mulheres alcancem cargos de comando. Nesse sentido, 
o fenômeno do teto de vidro (glass ceiling phenomenon), caracterizado em 1986, nos Estados Unidos por Hymowitz $e$ Schellhardt (1986), em artigo publicado no Wall Street Journal com o título de "The glass ceiling: why women cant seem to break the invisible barrier that blocks them from the top jobs". Este artigo fora motivado pela percepção dos autores sobre uma nova realidade de inserção da mulher no mercado de trabalho estadunidense, mas que ao mesmo tempo colidia com a disparidade de gênero no que tange ao acesso das mulheres aos cargos de gestão, no qual a imensa maioria dos cargos de gerência e liderança eram ocupados por homens (Carneiro, Frare e Gomes, 2019, p. 2).

Enquanto o piso pegajoso está umbilicalmente ligado ao plano horizontal, no teto de vidro

A segregação vertical, por sua vez, ocorre quando a maioria dos trabalhadores que ocupam os postos mais elevados de determinada profissão é formada por homens, ao passo que a maioria dos trabalhadores que ocupam os escalões mais baixos é composta por mulheres. Grosso modo, em todos os ramos profissionais observa-se que, à medida que se ascende na escala profissional, aumenta a presença masculina. Significa dizer que os homens também estão mais concentrados nos escalões superiores de todos os setores econômicos, nas esferas de comando, chefia, gerência, diretoria e presidência das empresas. O fenômeno que ficou conhecido pela metáfora do "teto de vidro" (glass ceiling) alude justamente a essa situação: às barreiras invisíveis que impedem as mulheres de ascender aos níveis hierárquicos mais elevados (Fernandez, 2019, p. 89).

Do teto de vidro decorre a ausência de mulheres em cargos de direção, pois quanto mais prestígio houver no cargo, menos mulheres encontraremos. Exemplo disso, é a própria direção do Brasil que, em mais de 500 anos de existência contou com apenas uma mulher em seu comando, Dilma Roussef, a qual foi arrancada pelo sexismo, machismo e misoginia, além de sofrer toda sorte de violência por ser mulher, tendo sua competência constantemente questionada, chegando a ser chamada de PresidANTA, uma espécie de “derivação parassintética” do substantivos Presidente + Anta (animal mamífero), uma vez que

Dilma começou subvertendo o português e foi amplamente criticada por exigir que fosse chamada de PresidentA, palavra cujo feminino deveria ser precedido apenas pelo artigo A. Nessa quase imposição, em que Dilma acabou por demonstrar um pouco da sua força no comando, de um poder que esteve sempre concentrado nas mãos de homens, começou a desagradar. Em seguida, de presidenta, virou presidanta, associando-a com ANTA. A primeira mulher no mais alto cargo do país começou a ter sua competência questionada assim que mexeu no mundo das palavras de poder nas quais não deveria caber a derivação feminina. Na verdade, tal poder não poderia estar nas mãos de uma mulher, a política machista não aceitaria isso de forma pacífica (Proner et. al., 2016, p. 86)

Nesse sentido, existe uma relação direta entre o capitalismo e subjugação das mulheres, que doentiamente as retira da participação social e as coloca em casa para a realização do trabalho doméstico a fim de possibilitar a engorda do capital, uma vez que esse trabalho não remunerado reproduz a força de trabalho, que são as crianças geradas em nos ventres das mulheres, as quais se transformarão em peças fundamentais para o funcionamento da máquina de moer carne humana - o capitalismo por meio da excedente oferta de mão de obra barata.

Desta feita, a trajetória da mulher no mercado de trabalho se mostra bastante penosa com as barreiras da economia sexista que vai do piso ao teto, segregando e oprimindo as mulheres tanto no plano horizontal quanto no vertical - piso pegajoso (sticky floor) e teto de vidro (glass ceiling), ferramentas insculpidas pelo sexismo que alicerçam o capital.

\section{Fenômeno Abelha Rainha (Queen Bee)}

Ao contrário do piso pegajoso e teto de vidro, onde os homens tem participação direta nas barreiras, no fenômeno "abelha rainha" a mulher é quem protagoniza o obstáculo às outra mulheres. No queen bee, aquelas que conseguiram desgrudar do piso pegajoso, quebrar o teto de vidro e ocupar espaços de poder, começam a reproduzir o sexismo e machismo a fim de impedir que outras mulheres ascendam na carreira e alcancem cargos de direção. Esse fenômeno (Unibrad, 2019, online) foi sugerido pela primeira vez em um estudo de 1973, de G.L. Staines, T.E. Jayaratne \& C. Tavris. Eles argumentaram que isso ocorria, em grande parte, porque a cultura patriarcal no trabalho encorajava as poucas mulheres que subiam ao topo a ficar inseguras de perder sua autoridade. 
As mulheres trilham caminhos tortuosos para atingir os cargos de direção, revelando verdadeiro "labirinto", uma vez que

o caminho do sucesso não é fechado para as mulheres, porém é restrito. Para os autores as mulheres atravessam uma espécie de "labirinto" como caminho até o sucesso, no qual elas precisam lidar com dificuldades, devido ao preconceito implícito e às barreiras invisíveis, que homens não experimentam no ambiente de trabalho. Consequentemente algumas mulheres podem acabar por adotar o comportamento do fenómeno da "abelha rainha". Segundo Derks, Van Laar e Ellemers (2015) o fenómeno da "abelha rainha" acontece com algumas mulheres que ocupam cargos de liderança. Este fenómeno consiste no facto de mulheres buscarem o sucesso individual em detrimento do próprio grupo, ou seja, em detrimento de outras mulheres e, embora com este tipo de comportamento possam alcançar o sucesso individual, prejudicam outras mulheres que parecem menos adequadas para cargos de liderança semelhantes (Ellemers et al, 2012). O fenómeno da "abelha rainha" é desencadeado, normalmente, (1) quando as mulheres se encontram em organizações onde os cargos de gestão são em sua maioria compostos por homens (Ellemers et al, 2012), (2) quando experimentam uma ameaça à identidade social das mulheres no ambiente de trabalho, (3) quando não possuem uma forte identificação de género e (4) quando entendem que fizeram sacrifícios pessoais para alcançar o sucesso profissional (Derks, Van Laar \& Ellemers 2015).” (Cesário, 2019, p. 10-11, apud Derks, Van Laar \& Elements, 2015)

Um vez ocupando os cargos de gestão, essas mulheres "abelhas rainhas" passam a apresentar três comportamentos, quais sejam: a) autoapresentação masculina - que corresponde os estereótipos sobre as características dos líderes bemsucedidos (competitivos, assertivos, ambiciosos); b) distanciamento de outras mulheres - pois uma maneira de melhorar suas oportunidades pessoais em organizações dominadas por homens é se distanciando de outras mulheres e c) legitimação da hierarquia de gênero - onde essas abelhas rainhas ao se distanciarem de outras mulheres terminam por legitimar a desigualdade de gênero, seja concordando com os estereótipos negativos sobre as mulheres; seja negando a ilegitimidade de resultados negativos para as mulheres enquanto grupo; e não apoiando e, algumas vezes, se opondo a ações para lidar com a desigualdade de gênero (Cesário, 2019).

Desta forma, os economistas recorrem à metáfora da "abelha rainha" para ilustrar os desafios enfrentados pelas mulheres em processos contemporâneos de ascensão profissional,

em que segundo eles, a sociedade das abelhas apresenta três castas de indivíduos: a rainha, o zangão e as operárias, cujas funções se definem por sua própria natureza e ciclo de vida. A função da rainha é pôr os ovos que darão origem à próxima rainha, aos próximos zangões e a todas as operárias. A abelha rainha possui características importantes e é a base da colmeia, já que é a única fêmea fértil. Caso nasça mais de uma abelha rainha, somente a primeira sobrevive. Aos zangões cabe apenas fecundar a rainha. Tendo cumprido a função, eles vêm a morrer. Já as operárias são as fêmeas estéreis da colmeia. Desse modo, como na colmeia, a vida corporativa apresenta indivíduos do sexo feminino integrados a estruturas dominadas por homens, dando origem ao fenômeno "abelha rainha", onde é imputada às mulheres que buscam realização profissional em espaços dominados por homens e que, em lugar de buscar apoio em outras mulheres, distanciam-se delas. Com essa atitude, acabam por se ajustar mais à cultura masculina que à feminina, retroalimentando-a (Miltersteineret. al, 2020, p. 410, apud Arvatea, Galileab e Todescatc, 2018; Derks, Van Laarb e Ellemer, 2016).

Para Derks, Van Laarb e Ellemers, os motivos desse comportamento é a competição e a sobrevivência, uma vez que, desde a infância, a mulher aprende que deve ser a melhor para conquistar o casamento perfeito, entrando em uma disputa natural com outras figuras femininas e ao atingir a vida adulta, essa cultura presente em seu subconsciente expõe as mulheres a comportamentos organizacionais de maior competição, além de uma forma de sobrevivência em resposta à discriminação e à ameaça que tais indivíduos experimentam nos ambientes de trabalho, levando as mulheres a assimilarem definições masculinas de liderança à medida que sobem na hierarquia organizacional. (Miltersteiner et. al, 2020, p. 410, apud Derks, Van Laarb e Ellemers, 2016, p. 37) 
Assim, o fenômeno da "abelha rainha" adotado por mulheres desprovidas de sororidade ${ }^{2}$ ou dororidade ${ }^{3}$ - que não agem com sentimento de irmandade - promovem verdadeira exclusão e opressão às demais mulheres, copiando os comportamentos machistas que culmina no levantamento de uma terceira barreira do modelo econômico sexista a serem enfrentada pelas mulheres, onde o sólido se desintegra no ar e reclama pela conclamação das proletariadas de todos os países para uni-vos! (Marx, Engels, 2019).

\section{Consequências da Economia Sexista}

A economia sexista amamenta o capitalismo, que retira todo colostro dos corpos femininos, degradando-os, enquanto é imunizado de toda e qualquer crise que possa destruí-lo - incluindo a pandemia por COVID-19 - que resulta em efeitos avassaladores, pois aprofunda severamente as desigualdades sociais. Segundo relatório da ONG britânica Oxfam “a desigualdade econômica está fora de controle. Uma das principais razões para aprofundar o fosso entre ricos e pobres, aponta o trabalho, é um sistema econômico mundial sexista" (O Globo, 2020, online).

Nesse relatório, verificou-se que, pelo menos 12,5 bilhões de horas de trabalho gratuitas, desempenhada pelas mulheres todos os dias, que são ignoradas pelos governos e empresas, tornando invisíveis os trabalhos de cuidar de outras pessoas, cozinhar, limpar, buscar água e lenha, essenciais para o funcionamento da economia, mas são desvalorizado pela economia que valoriza apenas o reduzido grupo dos mais ricos no mercado. Como resultado disso, o Estado composto de bases capitalistas, cujo lucro é aumentado exponencialmente com os frutos desse trabalho não remunerado, uma vez que não investir dinheiro em construção de creches, nem mesmo gastar com cuidado de idosos ou pessoas acometidos de doença crônica, por exemplo. Dessa forma, "na mesma medida em que a burguesia, isto é, o capital se desenvolve, desenvolve-se também o proletariado, a classe dos operários modernos, os quais só vivem enquanto têm trabalho, e só tem trabalho enquanto o seu trabalho aumenta o capital" (Marx, Engels, 2019, p. 56)

Salienta-se que, a ampliação da desigualdade social resultante da economia sexista, violenta mais perversamente as mulheres negras que estão localizadas no ponto da encruzilhada, sendo atravessada pela opressão de gênero, raça e classe, onde

tais sistemas, frequentemente, se sobrepõem e se cruzam, criando intersecções complexas nas quais dois, três ou quatro eixos se entrecruzam. As mulheres racializadas frequentemente estão posicionadas em um espaço onde o racismo ou a xenofobia, a classe e o gênero se encontram. Por consequência, estão sujeitas a serem atingidas pelo intenso fluxo de trafego em todas essas vias (Crenshaw, 2012, p. 177).

Nesse sentido, as mulheres negras sofrem de forma mais acentuada os efeitos da economia sexista e acabam engrossando a base da pirâmide social, sendo encontradas em setores profissionais menos favorecidos como, por exemplo, empregadas domésticas, as quais foram as mais sufocadas em 2020 pela pandemia por COVID-19, pois não foram dispensadas de suas funções, além de ser considerada como serviço essencial por alguns Estados como Pará e Pernambuco. Tudo isto culminou na infecção de pessoas negras faveladas, como ocorrido com Cleonice Gonçalves, primeira vítima fatal da doença no Rio de Janeiro. Embora com idade avançada e os problemas de saúde de uma empregada doméstica, Cleonice, 63 anos, percorria semanalmente $120 \mathrm{~km}$ de sua casa humilde em Miguel Pereira, no sul fluminense, até o apartamento onde trabalhava no Alto Leblon, bairro da zona sul do Rio que tem o metro quadrado mais valorizado do país, tendo sido infectada por sua patroa que adquiriu Covid-19 na Itália (Carta Capital, 2020, online).

\footnotetext{
${ }^{2}$ É derivado do latim soror, que significa irmã, logo, sororidade constitui uma irmandade entre as mulheres, isto é, união e força entre elas para alcançar objetivo em comum, sem competição, pois juntas as vozes femininas ecoa mais forte e mais longe.

${ }^{3}$ Dororidade, em apertada síntese, é uma dor preta, cuja união, irmandade é aplicável às mulheres negras, que sofrem com a dor do racismo. $\mathrm{O}$ termo dororidade foi cunhado pela autora preta Vilma Piedade.
} 
As sobreviventes dessa economia sexista sofrem a dor da morte decorrente da marginalização de suas crianças, onde se veem obrigadas a ausentarem do lar e cuidados de seus filhos para conseguir prover os alimentos necessários à sobrevivência, o que torna suas proles disponíveis para execução do projeto racista oficializado pelo Estado, que ceifa a vida de centenas de crianças negras no Brasil por "tiro acidental" da Polícia Militar. Além do Estado, a sociedade participa "ativamente" desse "acidente", como ocorrido com o filho da empregada doméstica, Mirtes Renata, que foi obrigada a sair para passear com o cachorro da patroa, empreendendo todo o zelo com o animal doméstico, enquanto seu filho teve sua vida ceifada por "despencar" da Casa-Grande.

Por outro lado, esse modelo econômico provoca a degradação e exclusão generalizada das mulheres conseguindo atingir inclusive pesquisadoras em home office - resultado da pandemia por COVID-19 - que culminou na redução da submissão de artigos assinados por mulheres como efeito da economia sexista que atribuem responsabilidade dos afazeres domésticos, cuidados dos filhos e trabalho em casa, enquanto os homens pesquisadores gozam de longos períodos em casa integralmente aplicados na confecção de trabalhos científicos.

Conforme (Uol, 2020, online) resultado preliminar do Projeto Parent Science, que analisa o impacto do isolamento social na conclusão do trabalho, mais da metade das mães pesquisadoras deixaram de produzir artigos. Segundo esses dados preliminares, $40 \%$ das mulheres sem filhos não concluíram seus artigos, contra $20 \%$ dos homens e, $52 \%$ das mulheres com filhos não concluíram seus artigos, contra 38\% de homens, o que pode ser explicado pelos dados do Instituto Brasileiro de Geografia e Estatística (IBGE) demonstrando que as mulheres gastam o dobro de tempo em afazeres domésticos que os homens, mesmo quando ocupam cargos similares ao dos homens.

Dessa forma, a economia sexista é principal alicerce do capital responsável pelas mazelas da sociedade, que culmina no aprofundamento das desigualdades sociais refletindo no aumento assustador da fome e toda sorte de violência, como por exemplo, a violência doméstica e feminicídio, onde os números aumentaram exponencialmente em todo o país durante o isolamento social.

\section{Considerações Finais}

O piso pegajoso, teto de vidro e abelha rainha constituem barreiras ao crescimento das mulheres no exercício de suas funções, profissões e de seus trabalhos, e, ainda, impedem a chegada das mulheres aos cargos de prestígio. Esta tripla combinação produz efeitos nefastos às vidas e aos trabalhos remunerados das mulheres, pois acaba por confiná-las aos afazeres domésticos, que por vezes não são remunerados, beneficiando sobremaneira o capitalismo e acentuando as desigualdades sociais.

Para furar as barreiras dispostas no plano horizontal (piso pegajoso), que segrega as mulheres em atividades intimamente ligadas ao dever de cuidado e domésticas em geral e plano vertical (teto de vidro), concentrando-as em cargos de menos prestígio - é necessária a implantação de políticas de inclusão de mulheres negras, pois conforme lição de Karl Marx "o trabalho de pele branca não pode se emancipar onde o trabalho de pele negra é marcado a ferro" (Marx, 2017, p. 372, edição kindle).

Outrossim, é imprescindível a união das mulheres e sentimento de irmandade disposto pela sororidade e/ou dororidade a fim de possibilitar o rompimento dessas estruturas sexistas fazendo com que àquelas mulheres que conseguiram romper todas as barreiras não fechem os caminhos para passagem de suas irmãs com a adoção de comportamentos previstos no fenômeno "abelha rainha", em que mulheres que ocupam cargos de gestão passam a oprimir e impedir que outras ocupem esses espaços de prestígio.

Assim, além da união entre as mulheres para romper as barreiras e as estruturas do machismo, sexismo e misoginia que servem de base para o capitalismo que reproduz toda forma de exclusão social, como racismo, feminicídio e demais violências - é 
imprescindível a adoção de um feminismo para os 99\%, que seja capaz de atacar a coluna dorsal de todas as mazelas sociais, possibilitando que mulheres ocupem espaços de poder sem que haja reprodução de novas abelhas rainhas, haja vista que "não temos interesse em quebrar o telhado de vidro enquanto deixamos que a ampla maioria limpe os cacos" (Aruzza; Bhattacharya; Fraser, 2019, p. 31).

\section{Referências}

Aruzza, C., Bhattacharya, T., \& Fraser, N. (2020). Feminismo para os 99\% - Um Manifesto. Tradução de Heci Regina Candiani. Boitempo.

Carneiro, L. B., Frare, A. B. \& Gomes, D. G. (2019). Teto de Vidro: Um estudo sobre os fatores deste fenômeno no Brasil sob a percepção de Mulheres Gestoras. XIX USP International Conference in Acoutting, 2019). https://congressousp.fipecafi.org/anais/19UspInternational/ArtigosDownload/1607.pdf.

Carta Capital (2020). Na pandemia, por que o serviço doméstico é classificado como essencial? https://www.cartacapital.com.br/blogs/sororidade-empauta/na-pandemia-por-que-servico-domestico-e-classificado-como-essencial/.

Cesario, C. V. (2019). Mulheres em cargo de liderança. Porto, 2019, 73 f. Dissertação (Mestrado em Economia). Universidade do Porto, Faculdade de Economia. https://repositorio-aberto.up.pt/bitstream/10216/123810/2/364807.pdf.

Crenshaw, K. (2012). Documento para o encontro de especialistas em aspectos da discriminação racial relativos ao gênero. Tradução de Liane Schneider. Los ângeles https://www.scielo.br/pdf/ref/v10n1/11636.pdf

Davis, A. (2016) Mulheres, raça e classe. Tradução de Heci Regina Candiani. Boitempo.

Federici, S. (2017) Calibã e a bruxa: mulheres, corpo e acumulação primitiva. Editora Elefante, 2017

Fernandez, B. P. M. (2019) Teto de vidro, piso pegajoso e desigualdade de gênero no mercado de trabalho brasileiro à luz da economia feminista: por que as iniquidades persistem? Cadernos de Campo (UNESP), 26, 79-103, 2019.

Folha Dirigida. (2020) Os desafios da igualdade de gênero no mercado de trabalho. https://folhadirigida.com.br/mais/noticias/especiais/os-desafios-daigualdade-de-genero-no-mercado-de-trabalho.

Louro, G. L. (1997) Gênero, sexualidade e educação. Uma perspectiva pós-estruturalista. Vozes

Marx, K.\& Engels, F. (2019) Manifesto do Partido Comunista. Tradução, prefácio e notas de Edmilson Costa. Edipro

Marx, K. (2017) O Capital - Livro I. Tradução de Rubens Enderle. Boitempo

Miltersteiner et. al. (2020). Liderança Feminina: percepções, reflexões e desafios na administração pública. Revista FVG, Cad. EBAPE.BR, 18 406-423.

O Globo. (2020) Economia sexista aprofunda desigualdade mundial, diz pesquisa da Oxfam. https://oglobo.globo.com/celina/economia-sexista-aprofundadesigualdade-mundial-diz-pesquisa-da-oxfam-1-24199855.

Paulino, W. R. (2002) Biologia. Ática 32-36.

Piedade, V. (2017) Dororidade. Nós

Proners et. al. (Orgs.). (2016) A resistência ao golpe de 2016. Canal 6

Unibrad. Síndrome da Abelha Rainha perde força. https://www.unibrad.com.br/artigo-detalhe/4099/sindrome-da-abelha-rainha-perdeforca\#: :text=Ou\%20seja\%2C\%20aquela\%20profissional\%20bem,Jayaratne\%20\%26\%20C.

Uol. (2020) Produção científica de mulheres despenca na pandemia - de homens, bem menos. https://www.uol.com.br/tilt/noticias/redacao/2020/05/26 /pandemia-pode-acentuar-disparidade-entre-homens-e-mulheres-na-ciencia.htm 